\title{
Correction to: Imaging Predictors of Vasospasm and Delayed Cerebral Ischaemia After Subarachnoid Haemorrhage
}

Isabel Fragata, MD, PhD ${ }^{1,2, *}$ 。 Bruno Cunha, $M D^{1,2}$

Patrícia Canhão, MD, PhD ${ }^{3,4}$

\author{
Address \\ ${ }^{1}$ Neuroradiology Department, Hospital São José, Centro Hospitalar Universitário \\ de Lisboa Central, Lisbon, Portugal \\ ${ }^{*}, 2$ NOVA Medical School, Universidade Nova de Lisboa, Lisbon, Portugal \\ Email: isabelfragata@gmail.com \\ ${ }^{3}$ Department of Neurosciences and Mental Health, Department of Neurology, \\ Hospital de Santa Maria, CHLN, Lisbon, Portugal \\ ${ }^{4}$ Universidade de Lisboa, Faculdade de Medicina, Instituto de Medicina Molecular, \\ Lisbon, Portugal
}

Published online: 5 January 2021

(C) Springer Science+Business Media, LLC, part of Springer Nature 2021

The online version of the original article can be found at https://doi.org/10.1007/s11940-020-00653-1

A correction to this paper has been published: https://doi.org/10.1007/s11940-02000658-w

Correction to: Curr Treat Options Neurol (2020) 22:12

https://doi.org/10.1007/s11940-020-00653-1

In the recently published review of "Imaging Predictors of Vasospasm and Delayed Cerebral Ischaemia After Subarachnoid Haemorrhage", the name of the last author has a change in formatting. This should be corrected from PatrU' cia CanhĐo to Patrícia Canhão.

The original article has been corrected. 


\section{Publisher's Note}

Springer Nature remains neutral with regard to jurisdictional claims in published maps and institutional affiliations. 